\title{
Evolution in Biology Education: Sparking Imaginations and Supporting Learning
}

\author{
Kristin P. Jenkins
}

Published online: 8 August 2009

(C) Springer Science + Business Media, LLC 2009

Recently, I have been reading Darwin's The Voyage of the Beagle. I am struck by Darwin's enthusiasm and interest in everything - from geology, to natural history, to cultures. His willingness to undertake uncomfortable journeys, eat weird foods, and mingle with people very different from himself is far removed from the way I typically think of him - as a retired, country gentleman with a delicate constitution. But his enthusiasm and curiosity remain undiminished in his later years, and I find myself wondering how to convey this excitement to students. I suspect that the same questions and evidence that captured Darwin's imagination can still capture theirs.

In the 150 years since Darwin laid out his ideas in The Origin of Species, it has been observed repeatedly that evolution is a key biological principle critical for understanding the living world. It makes sense then that biology courses should be permeated with evolutionary theory. Evolution provides a natural interdisciplinary conduit both across biological fields and beyond biology to other disciplines such as geology. It gives scientists a common frame of reference for discussions, which can result in novel interdisciplinary research and even new fields such as evo-devo (studying evolution from an evolutionary viewpoint). Beyond academia, evolution plays a very practical and important role in many applied fields such as agriculture, public health, and conservation which impact

K. P. Jenkins $(\square)$

Education and Outreach Program, NESCent,

Durham, NC, USA

e-mail: kjenkins@nescent.org everyone's daily life. Clearly, evolution remains an exciting and important field with many interesting questions yet to be answered.

One way to convey the excitement of Darwin and other scientists is to use evolution as a conceptual framework for teaching biology. This is not a new idea, but there is a growing interest in this approach. It turns out that using an evolutionary framework to teach biology is also a pedagogically sound approach. Science education research informs us that new knowledge is placed in a mental scaffold or framework of conceptual knowledge (Ausubel 2000). Instructors can help their students acquire disciplinary knowledge by providing an appropriate scaffold (Bransford et al. 1999; Handelsman et al. 2007). In addition, evolutionary theory is a classic example of the nature of science (Working Group on Teaching Evolution 1998). Majors and non-majors alike benefit from a solid understanding of the nature and process of science, and all the more so if the example is based on biology that impacts them personally.

Teaching from an evolutionary viewpoint does not require instructors to change the content of their classes or even radically alter how they present content. Instead, when instructors view course material through an evolutionary lens, that viewpoint is conveyed to students. Particularly in introductory biology classes, which cover a broad range of seemingly disconnected topics, evolution provides a link between ideas ranging from genetics to ecology and gives students a platform from which to explore both the patterns and processes of life. This thematic approach guides students to think about the larger questions - why things are the way they are and how they came to be that way.

Many groups are working on ways to promote this idea, either through providing resources, revising courses, or developing appropriate curricula. A working group at the 
National Evolutionary Synthesis Center titled appropriately, Evolution Across the Curriculum, has been thinking about ways to support the broad scale adoption of this approach for introductory college courses, including community colleges where many of our students take their introductory biology courses. The group is developing a collection of background resources for instructors to support an evolutionary viewpoint in teaching across the broad range of material covered in an introductory course. Another outcome from the NESCent group is a public database of projects designed to facilitate evolutionary themed instruction. You can learn more about the working group and provide suggestions for the format and content of the background resources at: http://www.nescent.org/eog/exemplars.php. If you have a project promoting teaching with an evolutionary viewpoint or simply a group of interested peers at your institution, the working group at NESCent would like to hear from you.

In this issue of Evolution: Education and Outreach, readers will find a range of papers about using an evolutionary theme to teach biology. There are interesting lab (Kuzoff et al. 2009; Smith and Cheruvelil 2009) and course activities and demonstrations of the use of technology to explore evolutionary concepts (Speth et al. 2009; Abraham et al. 2009). The regular column from Understanding Evolution describes a collection of classroom ready examples of current evolutionary research (Thanukos 2009). Other papers provide examples of interdisciplinary and integrative programs for reaching a broad range of students (O'Brien et al. 2009; Nadelson et al. 2009). This issue also includes papers highlighting the connection between understanding the Nature of Science and evolution (Ladine 2009; McCrory and Murphy 2009). NCSE provides information on the value and impact of science standards in their regular column and a report on current science standards (Scott 2009; Mead and Mates 2009), which is nicely complimented by a paper about a successful professional development program that reaches out to include school boards and administrators (Johnson et al. 2009). What these papers have in common is a shared interest in improving the educational experience for students and encouraging their interest in biology. The range of topics makes it clear that goal can be achieved using a variety of novel ideas and approaches and also demonstrates that many instructors are actively engaged in sharing their interest in evolution with students. We hope that readers will find the authors' experiences helpful in developing their own projects and encourage them to share their own enthusiasm with their peers in this journal and with their students in the classroom.
Acknowledgements It has been my pleasure and privilege to serve as guest editor for this edition of Evolution: Education and Outreach. I thank Niles Eldredge, Greg Eldredge, Mick Wycoff, and Adam Goldstein for showing me the ropes, the Springer editorial staff for answering my many questions, reviewers for their time and thoughtful comments, and the many contributors for sharing their insight and wonderful projects. Thanks also to Paul Beardsley for his helpful comments on this piece.

\section{References}

Abraham JK, Meir E, Perry J, Herron JC, Maruca S, Stal D. Addressing undergraduate student misconceptions about natural selection with an interactive simulated laboratory. Evo Edu Outreach. 2009;2(3). doi:10.1007/s12052-009-0142-3.

Ausubel D. The acquisition and retention of knowledge: a cognitive view. Boston: Kluwer; 2000.

Bransford JD, Brown AL, Cocking RR. How people learn: Brain, mind, experience and school. Washington, DC: National Academies Press; 1999.

Handelsman J, Miller S, Pfund C. Scientific teaching. San Francisco: Freeman; 2007.

Johnson JB, Adair M, Adams BJ, Fairbanks DJ, Itamura V, Jeffery DE, et al. Evolution education in Utah: a state office of educationuniversity partnership focuses on why evolution matters. Evo Edu Outreach. 2009;2(3). doi:10.1007/s12052-009-0145-0.

Kuzoff RK, Kemmeter SB, McKinnon JS, Thompson CP. Phylogenetic analysis: how old are the parts of your body? Evo Edu Outreach. 2009;2(3). doi:10.1007/s12052-009-0157-9.

Ladine TA. Attitudes of students at a private christian liberal arts university toward the teaching of evolution. Evo Edu Outreach. 2009;2(3). doi:10.1007/s12052-009-0147-y.

McCrory C, Murphy C. The growing visibility of creationism in Northern Ireland: are new science teachers equipped to deal with the issues? Evo Edu Outreach. 2009;2(3). doi:10.1007/s12052-009-0141-4.

Mead LS, Mates A. Why science standards are important in a strong science curriculum and how states measure up. Evo Edu Outreach. 2009;2(3). doi:10.1007/s12052-009-0155-y.

Nadelson LS, Culp R, Bunn S, Burkhart R, Shetlar R, Nixon K, et al. Teaching evolution concepts to early elementary school students. Evo Edu Outreach. 2009;2(3). doi:10.1007/s12052-009-0148-x.

O'Brien DT, Wilson DS, Hawley PH. Evolution for everyone: a course that expands Darwin's theory beyond the biological sciences. Evo Edu Outreach. 2009;2(3). doi:10.1007/s12052009-0161-0.

Scott EC. Science standards evolve. Evo Edu Outreach. 2009;2(3). doi:10.1007/s12052-009-0153-0.

Smith JJ, Cheruvelil KS. Using inquiry and tree-thinking to "march through the animal Phyla": teaching introductory comparative biology in an evolutionary context. Evo Edu Outreach. 2009;2(3). doi:10.1007/s12052-009-0156-x.

Speth EB, Long TM, Pennock RT, Ebert-May D. Using Avida-ED for teaching and learning about evolution in undergraduate introductory biology courses. Evo Edu Outreach. 2009;2(3). doi:10.1007/ s12052-009-0154-z.

Thanukos A. From newsroom to classroom. Evo Edu Outreach. 2009;2(3). doi:10.1007/s12052-009-0144-1.

Working Group on Teaching Evolution. Teaching about evolution and the nature of science. Washington DC: National Academies Press; 1998. 